\title{
Neutrophil to Lymphocyte Ratio and Hs-CRP Predict Mortality in COVID-19 Patients
}

\author{
Evi Nurhayatun ${ }^{1,3}$ Nurhasan Agung Prabowo ${ }^{2,5}$ Dhani Redhono Harioputro ${ }^{6}$ Wachid \\ Putranto $^{4}$ Dono Indarto ${ }^{7}$ Bambang Purwanto ${ }^{8}$
}

\author{
1,2,3,4 Internal Medicine Department,Faculty of Medicine, Sebelas Maret University \\ ${ }^{5}$ Universitas Sebelas Maret Hospital \\ 6,7,8 Doctoral Program of Medical Sciences Faculty of Medicine Sebelas Maret University \\ *Corresponding author. Email: evi.nurhayatun@gmail.com
}

\begin{abstract}
Background: Inflammation plays an important role in the pathogenesis of COVID-19 and can be an important factor in the prognosis. The innate immune response to a respiratory infection is characterised by an influx of neutrophils to the lungs, particularly the alveoli. A sustained release of anti-inflammatory cytokines may lead to widespread apoptosis of lymphocytes, resulting in lymphopenia. Hs-CRP is an indicator of COVID-19 inflammation. The aim of this study was to analyse Neutrophilto-Lymphocyte Ratio (NLR) and Hs-CRP in order to predict mortality in COVID-19 patients. Research methods: This research was conducted at Moewardi Hospital in July 2020. The subjects were COVID-19 patients. NLR is neutrophils divided by lymphocytes using a haematology analyser. The examination of Hs-CRP was conducted utilizing the ELISA method. Statistical test with an independent T-test and cox proportional hazard analysis with $\mathrm{p}<0.05$ was also used. Results: The results showed that Hs-CRP and NLR increased in COVID-19 patients who later died and obtained lower levels of surviving ( $p=0.001$ and $p$ $=0.11)$. Hs-CRP increased the risk of death for COVID-19 patients $(\mathrm{p}=0.18 ; \mathrm{HR}=1.036)$ and NLR also increased the risk of death for COVID-19 patients $(\mathrm{p}=0.08$; HR $=1.34$ ) Conclusion: Neutrophil-to-Lymphocyte Ratio and Hs-CRP predicted mortality in COVID-19 patients
\end{abstract}

Keywords: Neutrophil-to-Lymphocyte Ratio, Hs-CRP, mortality, COVID-19

\section{INTRODUCTION}

An epidemic case in the form of an unexplained lower respiratory tract infection has been detected in Wuhan, located in China's Hubei Province and reported on December 31, 2019. At the beginning of the disease, the cause was unknown and was called an aetiology threat pneumonia on February 11, 2020. WHO (World Health Organization) stated that this disease was COVID-19 or coronavirus disease. This disease is spreading very fast and, on March 11, 2020, COVID-19 was declared a global pandemic[1].

COVID-19 cases in Indonesia are increasing day by day. According to the Indonesian Ministry of Health on September 12, 2020, the accumulation of the cases was 214.746 people, while the patients under supervision were 53.638 people, cases of recovered patients were as many as 152.458 people, and the died cases were 8.650 people. The number of COVID-19 cases in Central Java was 17.460 cases or $8.1 \%$ of the national total, active cases that were still being treated were 5.352 people, with a cured rate of 10.969 , and death rate of 1.139 people. Based on the total cases, Central Java ranks third nationally.[2]

The COVID-19 pandemic is quite worrying because of the widespread and high mortality rates. The death rate of
COVID-19 ranges from $0.75 \%$ to $3 \%$ and may decline in the future. Mortality is the main factor in determining whether infectious diseases are of public concern and the risk of causing a pandemic or not.[3] Chen et al. reported that the COVID-19 mortality rate was $11 \%$ based only on patients whose condition was in urgent treatment.[4]

This viral infection can produce an overactive immune reaction in humans. This reaction is called a cytokine storm, which results in tissue damage with impaired coagulation. Various kinds of cytokines play a role in this disease's pathogenesis, one of which is interleukin 6 . IL 6 plays a role in the acute phase production, and one of them is Hs-CRP. Several indications of inflammation and immune status are potential predictors of prognosis of COVID-19 patients. The NLR has been widely studied as a predictor of the prognosis of patients with viral pneumonia.[5]

To date, there is no specific anti-viral therapy for COVID-19 and no vaccine is available.[1] Therefore, it is crucial to look for factors that can predict mortality in COVID-19 patients that it will be the signal when the patients meet the predictors of death so that they will be treated in an intensive room and get a maximum treatment immediately. Thus, this study aimed to analyse NLR and Hs-CRP to predict mortality in COVID-19 patients. 


\section{METHODS}

This research was conducted at Moewardi Hospital in July 2020. The subjects were COVID-19 patients who had laboratory examinations of Hs-CRP and NLR. NLR is neutrophil divided by lymphocytes using a haematology analyser. The examination of Hs-CRP was conducted utilizing the ELISA method. Statistical test with an independent $\mathrm{T}$-test and cox proportional hazard analysis with $\mathrm{p}<0.05$ was also used.

\section{RESULTS}

This study is a retrospective study by looking at the medical records of the patients hospitalized in the COVID19 ward. This study was conducted on patients with a proper diagnosis of COVID-19 based on PCR results. The results showed that NLR 4,25 + 3,27 and Hs-CRP 5,46+15,39 $\mathrm{mg} / \mathrm{L}$ with mortality occurred in 8 patients.

Table 1. Baseline characteristic of the research subject

\begin{tabular}{ccccc}
\hline Variables & Survivor & Death & $\mathrm{p}$ & Total \\
\hline $\mathrm{N}$ & 41 & 8 & 0,001 & 49 \\
Male & 25 & 6 & & 31 \\
Female & 16 & 2 & & 18 \\
& $48,5+$ & $55,88+$ & & $49,33 \pm$ \\
Age & 17,83 & 7,06 & 0,001 & 16,76 \\
& $1,89 \pm$ & & & $2,25 \pm$ \\
NLR & 2,43 & $4,13 \pm 3,75$ & 0,001 & 3,27 \\
Hs-CRP & $1,85 \pm$ & $19,9 \pm$ & & $5,46 \pm$ \\
(mg/L) & 2,70 & 31,47 & 0,001 & 15,39 \\
\hline
\end{tabular}

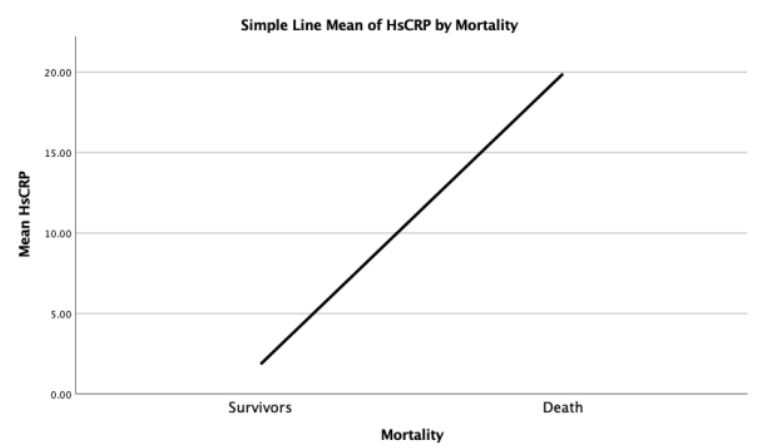

Fig.1. Correlation between the Hs-CRP level and mortality rate in COVID-19 patients

Hs-CRP increased the risk of death for COVID-19 patients $(\mathrm{p}=0.18 ; \mathrm{HR}=1.036)$. This study shows an increase in Hs-CRP correlates with the death rate; the higher the Hs-CRP, the mortality rate also will be higher. Therefore, it could be a predictor of mortality in COVID-19 patients.

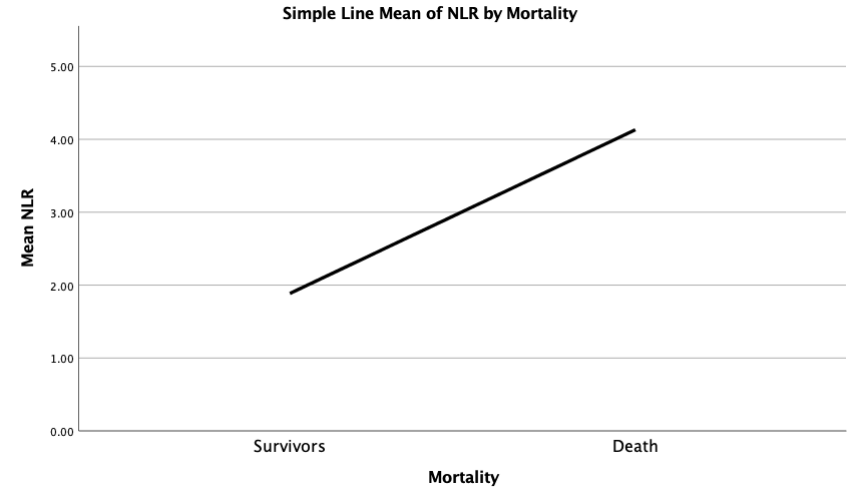

Fig.2. Correlation between the NLR and mortality rate in COVID-19 patients

NLR also increased the risk of death for COVID-19 patients $(\mathrm{p}=0.08 ; \mathrm{HR}=1.34)$. This study shows an increase in NLR correlates with the death rate; the higher the NLR, the mortality rate also will be higher. Therefore, it could be a predictor of mortality in COVID-19 patients.

\section{DISCUSSION}

This study proves that NLR is one of the predictors of the death of COVID-19 patients. This study included 49 COVID-19 patients and the total in-hospital mortality was 8. Most of the patients showed a higher number of neutrophils and a lower number of lymphocytes. The increase of NLR was found in nonsurvivors with COVID19 compared to survivors. This study followed previous studies that NLR is an indicator of the prognostic of COVID-19 patients. Neutrophils are the main component in activated leukocytes and migration from the venous system into organs and neutrophils will release ROS that can cause DNA damage and damage viruses from within the cell so that cell-mediated cell-dependent antibodies will kill the virus directly through introduction against viral antigens and stimulation of specific and humoral immunity. Besides, neutrophils will interact with cell populations and produce various cytokines and effector molecules such as vascular endothelial growth factors. Also, neutrophils can be stimulated by pro-inflammatory cytokines released by viral response responses such as IL 6, IL 8 and TNF Alfa.[5]

The leukocyte immune response to physiological stresses such as tissue damage, major surgery, severe trauma and sepsis is characterised by an increase in the number of neutrophils and a decrease in lymphocytes. Inflammation stress is characterized by the percentage of neutrophils' ratio to the percentage of lymphocytes in the blood and is known as Neutrophil Lymphocyte Stress Factor (NLSF).[6]

The human immune response stimulated by infectious viruses depends on lymphocytes. In contrast, systemic inflammation will suppress cellular immunity, where a decrease in CD4 lymphocyte t cells and an increase in CD$8 \mathrm{t}$ cells suppressor $\mathrm{t}$ lymphocytes so that in the end, the virus will stimulate inflammation, which causes an increase in the NLR and NLR will cause the progression of COVID19 so that the clinical conditions will increase as well as the 
mortality.[5] Higher NLR significantly associated with an increased risk of death during hospitalization.[7]

C-reactive protein (CRP) is an acute inflammatory protein produced by the liver mainly as a reaction to IL-6 and that inflammatory marker can play a role in predicting severity in Community-Acquired Pneumonia.[8] In COVID-19 patients, CRP might be the expression of lung damage and the respiratory distress consequent to the abnormal inflammation status. CRP correlates with the diameter of the lung lesion.[9] CRP is an acute-phase protein that responsible for the clearance of pathogens by enhanced phagocytosis and complement system.[10]

The pathogenesis of COVID-19 infection is not well known. Cellular immune response and cytokine storms are suspected of playing an essential role in the severity of the disease. A study by Lu et al. stated that Hs-CRP plays an essential role as a predictor of the severity and mortality of COVID-19. Hs-CRP is an indicator of severe inflammation and Hs-CRP will increase rapidly and respond to inflammation by activating complement, which stimulates excessive cytokine production. Lu et al. study showed that Hs-CRP plays an essential role as a predictor of mortality in young adult COVID-19 patients.[11]

\section{CONCLUSION}

NLR and Hs-CRP predict mortality in COVID-19 patients. This study is one of the shreds of evidence that the NLR and Hs-CRP examination at the beginning of the diagnosis of COVID-19 can be a predictor of death in COVID-19 patients. Therefore, it will be the signal for clinicians when there are high Hs-CRP and NLR to get more intensive care.

\section{AUTHORS' CONTRIBUTIONS}

Data gathering and idea owner of this study, Study design, Data gathering, Writing and submitting manuscript, Editing and approval of final draft, all events done by all the authors. All authors read and approved the final manuscript.

\section{ACKNOWLEDGMENTS}

The authors acknowledge the contribution of all research assistants involved in the collection of data. The authors express their profound gratitude to all participants in the study.

\section{REFERENCES}

[1] Cascella M, Rajnik M, Cuomo A, Dulebohn SC, Di Napoli R. Features, Evaluation, and Treatment of Coronavirus (COVID-19). In: StatPearls [Internet]. Treasure Island (FL): StatPearls Publishing; 2020 [cited 2020 Sep 14]. Available from: http://www.ncbi.nlm.nih.gov/books/NBK554776/

[2] Kementerian Kesehatan. Dashboard Kasus COVID-19 di Indonesia [Internet]. Dashboard Kasus COVID-19 di Indonesia. 2020 [cited 2020 Sep 13]. Available from: https://www.kemkes.go.id/article/view/20031900002/ Dashboard-Data-Kasus-COVID-19-di-Indonesia.html
[3] Wang L, Li J, Guo S, Xie N, Yao L, Cao Y, et al. Realtime estimation and prediction of mortality caused by COVID-19 with patient information based algorithm. Science of The Total Environment. 2020 Jul;727:138394.

[4] Epidemiological and clinical characteristics of 99 cases of 2019 novel coronavirus pneumonia in Wuhan, China: a descriptive study

[5] Yang A-P, Liu J, Tao W, Li H. The diagnostic and predictive role of NLR, d-NLR and PLR in COVID-19 patients. International Immunopharmacology. 2020 Jul;84:106504.

[6] Chen XH, Yin YJ, Zhang JX. Sepsis and immune response. World J. Emerg. Med. 2011; 2:88-92.

[7] Liua Y, Dua X, Chena J , Jina Y, Penga L, Wang HX, Luoe M, Chena L, Zhao Y. Neutrophil-to-lymphocyte ratio as an independent risk factor for mortality in hospitalized patients with COVID-19. Journal of Infection. $2020 ; 81: 6-12$

[8] Chalmers JD, Singanayagam A, Hill AT. C-reactive protein is an independent predictor of severity in community-acquired pneumonia. The American journal of medicine, 2008 Mar 1;121(3):219-25

[9] Poggiali E, Zaino D, Immovilli P, et al. Lactate dehydrogenase and C-reactive protein as predictors of respiratory failure in CoVID-19 patients. Clin Chim Acta. 2020;509(January):135-138.

[10] Sahua BR , Kampab RK, Padhic A, Panda AK. 2020. C-reactive protein: A promising biomarker for poor prognosis in COVID-19 infection. Clinica Chimica Acta, Vol. 509, p. 91-94

[11] Lu Y, Huang Z, Wang M, Tang K, Wang S, Gao P, et al. Clinical Characteristics and Predictors of Mortality in Young Adults with Severe COVID-19 [Internet]. In Review; 2020 Sep [cited 2020 Sep 14]. Available from: https://www.researchsquare.com/article/rs-31386/v2 